Darwish, M., Mohsen, O., Mohamed, Y., and Al-Hussein, M. 2020. "Integrated Simulation and Lean Approach for Production Line Improvement in a Prefabricated Panelized Homebuilding Facility." In: Tommelein, I.D. and Daniel, E. (eds.). Proc. $28^{\text {th }}$ Annual Conference of the International Group for Lean Construction (IGLC28), Berkeley, California, USA, doi.org/10.24928/2020/0030, online at iglc.net.

\title{
INTEGRATED SIMULATION AND LEAN APPROACH FOR PRODUCTION LINE IMPROVEMENT IN A PREFABRICATED PANELIZED HOMEBUILDING FACILITY
}

\author{
Mohammad Darwish ${ }^{1}$, Osama Mohsen², \\ Yasser Mohamed ${ }^{3}$, and Mohamed Al-Hussein ${ }^{4}$
}

\begin{abstract}
The construction industry is increasingly adopting off-site construction to achieve better quality buildings, to reduce the environmental impact of construction activities, and to attain less schedule variability. When shifting the construction process to a factory, the project is less vulnerable to uncertainties, such as unexpected weather conditions, labour turnover, and material delivery disturbances. Panelized construction is a method in which walls, floors, and roofs are built-in panels at the factory and shipped for on-site assembly. This paper describes the simulation of a production line in a panelized modular home manufacturing facility with the aim of better understanding and improving the production processes associated, in particular, with the first phase of production, namely the multiwall panel production line. Discrete event simulation (DES) is used to investigate and analyze the existing facility processes in terms of production time. The goal is to enhance productivity, reduce work-in-progress, and decrease idle time. The panelized manufacturing facility in the presented study produces dozens of multiwall panels per day, ranging in length from 3 to 13 meters, and both interior and exterior walls are produced on the same production line, each having different physical properties. Applying lean concepts and philosophy, the simulation tool is used to explore various scenarios where the idle time can be identified and minimized as much as possible from a practical perspective.
\end{abstract}

\section{KEYWORDS}

Lean Construction, discrete event simulation (DES), prefabricated homebuilding, panelized construction, process improvement

1 MSc student, Civil and Envir. Engrg. Dept., Hole School of Constr. Engrg. and Mgmt., University of Alberta, Edmonton, AB, Canada, mdarwish@ualberta.ca, orcid.org/0000-0002-1363-7225

$2 \mathrm{PhD}$ candidate, Civil and Envir. Engrg. Dept., Hole School of Constr. Engrg. and Mgmt., University of Alberta, Edmonton, AB, Canada, omohsen@ualberta.ca, orcid.org/0000-0002-3992-9357

3 Prof., Civil and Envir. Engrg. Dept., Hole School of Constr. Engrg. and Mgmt., University of Alberta, Edmonton, AB, Canada, yaly@ualberta.ca, orcid.org/0000-0001-9170-9557

4 Prof., Civil and Envir. Engrg. Dept., Hole School of Constr. Engrg. and Mgmt., University of Alberta, Edmonton, AB, Canada, malhussein@,ualberta.ca, orcid.org/0000-0002-1774-9718 


\section{INTRODUCTION}

Prefabricated construction (PC) is becoming gradually adopted as an alternative approach to conventional construction methods due to its many advantages including improved quality of building components, reduced material waste, fewer delays, and increased safety, as the majority of the productive work is carried out in a controlled environment and is less exposed to extreme weather conditions. In the PC approach, building components are manufactured in a factory, shipped to the construction site, then assembled by site crews. Prefab construction researchers and practitioners are continuously searching for methods to improve productivity and enhance the process and product quality by adopting a lean construction approach, which reduces construction waste, improves quality, and minimizes safety incidents (Koskela 1992). Chauhan et al. (2019) discussed an approach to systematically evaluate the benefits, both monetary and non-monetary, of applying prefabrication to construction projects. Through the use of process simulation, different lean improvement scenarios can be investigated before committing the effort, time, and expenditure for physical implementation. Discrete-event simulation (DES) enables the examination of various PC scenarios, investigate different resource allocation strategies, and perform comprehensive analysis for the purpose of productivity improvements of repetitive processes (AbouRizk and Hajjar 2011). To facilitate developing a simulation study, the current state of a production line is captured and then used as an input into the simulation model. Then, the simulation model is used to predict the future performance of the production line, given the various proposed changes. The current state data for production lines are typically collected via manual time studies, or maybe readily available through an automated real-time data collection system such as a radio frequency identification (RFID) system.

The classical seven wastes originated from a mass-production context include overproduction, time on hand, transportation, processing, stock on hand, movement, and making defective parts. Koskela et al. (2013) discussed how these wastes do not cover some aspects found in construction, such as the design stage, and explored the potential of creating a list of wastes specific to this type of production. Nevertheless, time on hand is one of the wastes that are present in the PC, which is the focus of this research.

This paper presents the use of DES to analyze the current state of a semi-automated wall panel production line in a panelized modular home manufacturing facility in Edmonton, Canada. The objective is to propose practical improvements to the production process by investigating various alternative scenarios. This study follows on similar research studies that implemented DES to achieve leaner manufacturing by examining production line bottlenecks in a semi-automated setting. Alternative scenarios are proposed to reduce idle time, and hence reduce the time waste of the process. This approach is supported by an accurate element-based time study performed on the facility and actual production data obtained from an RFID production monitoring system.

A literature review on previous related work is included, and a methodology section follows, which includes a description of process flow, data collection, and the simulation model. Three different proposed scenarios are then discussed. The conclusion section summarizes the research results and future study recommendations.

\section{LITERATURE REVIEW}

Modularization and prefabrication have been proven to be an effective construction method when compared to traditional approaches as it reduces the construction time, cost, 
frequency of errors, and improve the site logistics and the construction safety (Hermes 2015). A review of the applications of discrete event simulation (DES) in lean construction was conducted to evaluate the implementation of DES in lean research (Shou et al. 2019). The authors indicated that several lean values could be obtained using DES, such as the evaluation of multiple lean scenarios in a production line to forecast and assess the associated outcomes. There are several simulation-based tools, one of which is Simphony.NET, which was developed by AbouRizk et al. (2014) as a complete computer system environment that offers the ability to model construction and production operations and analyze the results in both discrete-event and continues approaches. AbouRizk and Hajjar (2011) studied the application of simulation in construction by developing a framework to model a special purpose simulation (SPS). Schramm et al. (2008) discussed using DES as an effective managerial tool by presenting two case studies of production systems in house-building projects. They assessed different scenarios and established improved sequencing to reduce non-value adding activities. Gupta et al. (2012) used DES to investigate the relationship between labour productivity and inventory buffer levels, work-in-progress (WIP), for repetitive building projects based on lean principles. They concluded that buffers help counter the negative effects of variability on project performance. Velarde et al. (2009) investigated the potential improvement in the process flow of a modular housing manufacturing operations based on time and process study and the implementation of lean manufacturing tools. Akhavian and Behzadan (2011) presented dynamic data-driven application simulation (DDDAS) where real-time field data were collected and used to create a dynamic simulation model of construction projects. Lu (2003) presented a new simplified discrete-event simulation approach (SDESA) with the intent to simplify construction simulation.

Mohsen et al. (2018) used discrete-event simulation to model the floor operations at a cabinet manufacturing facility where different scenarios have been investigated for potential improvements. Ritter et al. (2017) developed a DES model to investigate process improvements in a wall panel production line in a modular home manufacturing facility where two proposed scenarios are discussed based on expert knowledge. The first proposal was to double the labour resources, where it was assumed to reduce task times by half. The second proposal was to invest in a semi-automated framing machine where it was assumed to reduce the time required to frame each stud on the wall panel by $75 \%$. Garza-Reyes et al. (2012) used DES to investigate the loss of balance in the work-load between the stations in a mobile home production line. Their objective was to achieve a leaner process using the trial and error approach by altering resource allocations throughout the production line. However, the optimum state was defined as the least balancing loss between stations without considering the total production time. Another gap in their research is the assumption of a linear relationship between the number of workers performing a task and the time required to complete it. Moghadam (2014) used the simulation approach in their study to estimate the labour requirement in the production line of a modular construction facility to meet a range of production goals along with evaluating the potential benefit of investing in a semi-automated machine. Altaf et al. (2016) presented an online simulation model of a prefabricated wall panel production line that uses an RFID system with the aim of providing real-time simulation results of the proposed work-load to the production control system. From a theoretical view point, Vrijhoef (2016) demonstrated, through two case studies in housing renovation projects, that lean work organization and industrialized product technology are interconnected and both approaches aim towards improved workflow and productive time. 


\section{METHODOLOGY}

The general strategy that guided the activities in this research study is divided into four main steps. These steps are contained in Figure 1 and are outlined in the subsequent sections: a) process flow, b) data collection, c) simulation model, and d) data analysis.

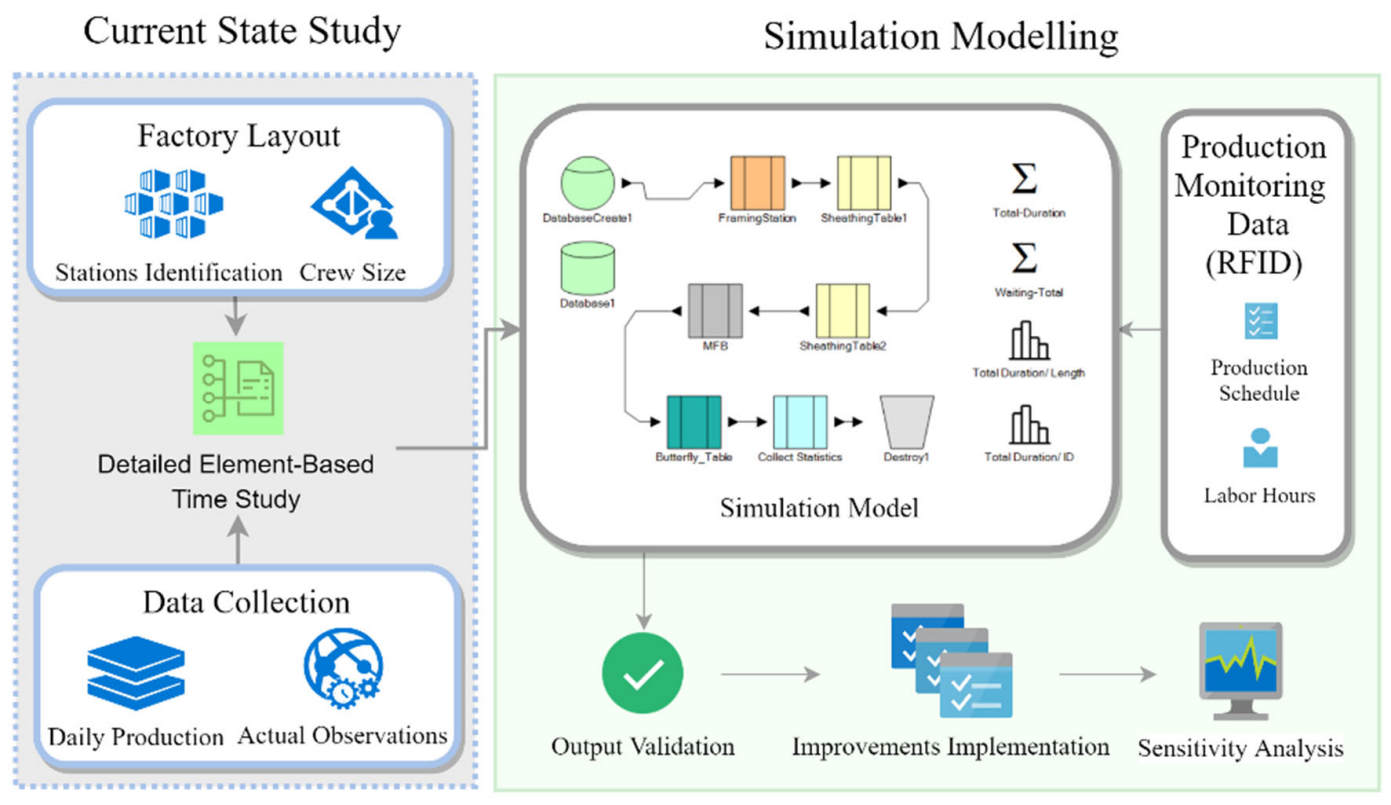

Figure 1: Research Methodology

\section{PROCESS FLOW AND DATA COLLECTION}

\section{Process Flow}

The simulation study starts with observing the daily operations at the panelized modular home manufacturing facility to identify the boundaries of the system and determine its relevant processes. Figure 2 shows the factory layout and the boundary of the current study, where the problem domain is restricted to the production line of multiwall panels.

The multiwall panel production line consists of five consecutive stations: a) framing station, b) sheathing station 1, c) sheathing station 2, d) multifunction bridge, and e) butterfly transfer table. The product, in this case, a wall panel, goes through these stations in sequence, and no two products can be processed at one station at the same time.

a) The framing station (FS) is the first station in the production line where workers load the studs into the machine in sequence, after which the machine nails the studs to the top and bottom plates of the wall panel.

b) Sheathing tables 1 (ST1) and 2 (ST2) are the second and third stations in the production line where one or more workers perform several manual tasks, including correcting errors that result from the framing machine, installing backing and other support material, and positioning and nailing sheathing boards for exterior walls.

c) The multifunction bridge (MFB) is the fourth station in the production line, where the sheathing boards are automatically fastened to the studs of the wall panel using nail guns that are mounted on the moving bridge. The sheathing boards are only installed on exterior walls. 
d) The butterfly table (BT) receives the wall panels after they pass the multifunction bridge. In this station, the multiwall panels are marked and cut into individual single panels for further processing before being ready to be shipped to the site.

\section{Data Collection}

The datasets that are related to the production of wall panels are used to develop the simulation model, and are collected from:

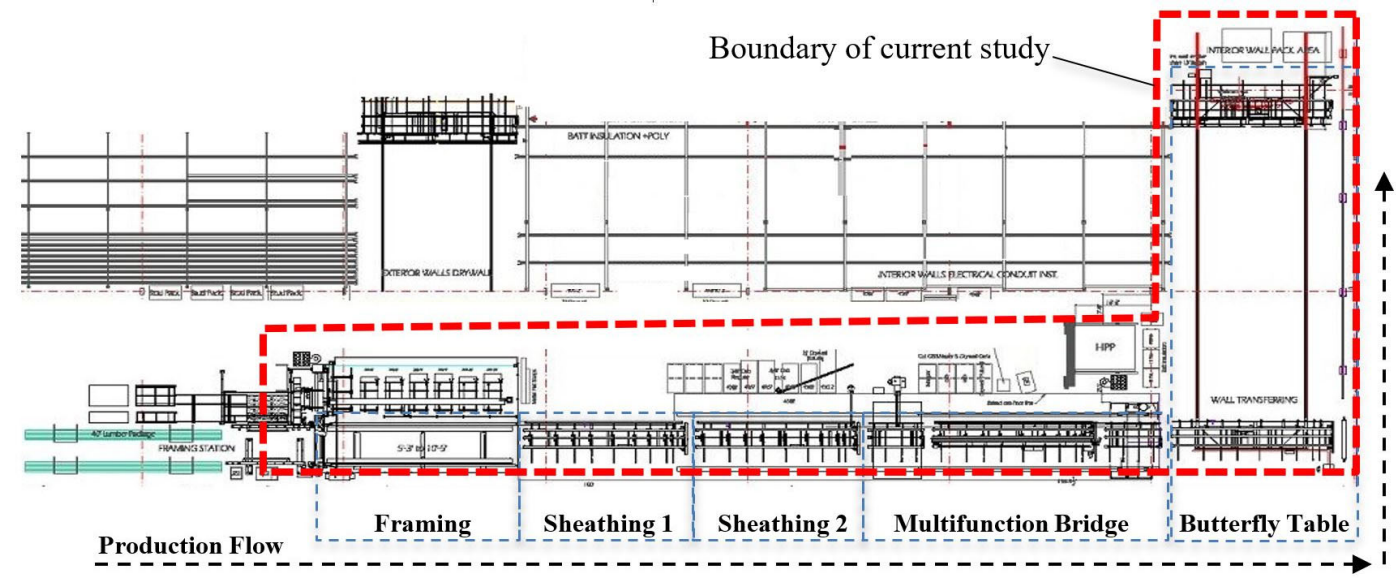

Figure 2: Factory Layout and the Boundary of the Current Study

e) the database containing product information, which includes the physical composition of each wall panel such as the number of studs, the number of windows and doors, etc., and

f) a time study conducted to measure how much time is needed to complete each operation such as nailing studs to top and bottom plates, moving the panel from one station to the next, laying out and installing sheathing, etc.

The physical properties of wall panels are collected for more than 2,900 panels. These wall panels correspond to the simulated entities in the simulation model, which is described in more detail in the next section.

\section{SIMULATION MODEL}

Computer simulation is used to test and forecast the output of several lean alternatives for the production system in the addressed facility. The development of the simulation model starts by collecting information about the system and process flow on it. A discrete-event simulation (DES) model was created using Simphony.NET. Experimentation with the model through a "what-if" analysis, as well as verification and validation, was performed throughout development until satisfactory results were obtained. The layout of the primary simulation model and the Framing Station part can be demonstrated in Figure 3.

The basic entity used in the simulation model is the wall panel. The modelling of operations starts with reading records stored in a local database file. Each entity represents a wall panel with all physical properties attached to it, such as the length and width of the panel, the number of studs, and the number of small and large openings. These physical properties are used for time calculations and to make branching decisions throughout the entity production cycle in the simulation.

Each wall panel, represented by a single entity, goes through a series of operations starting from 'FramingStation' moving to 'SheathingTable1' and 'SheathingTable2' then 
to the multifunction bridge 'MFB' and finishes the simulation at the 'Butterfly_Table'. Each of these stations is represented by a 'composite element' in the simulation, which encompasses several operations and activities related to those specific stations.

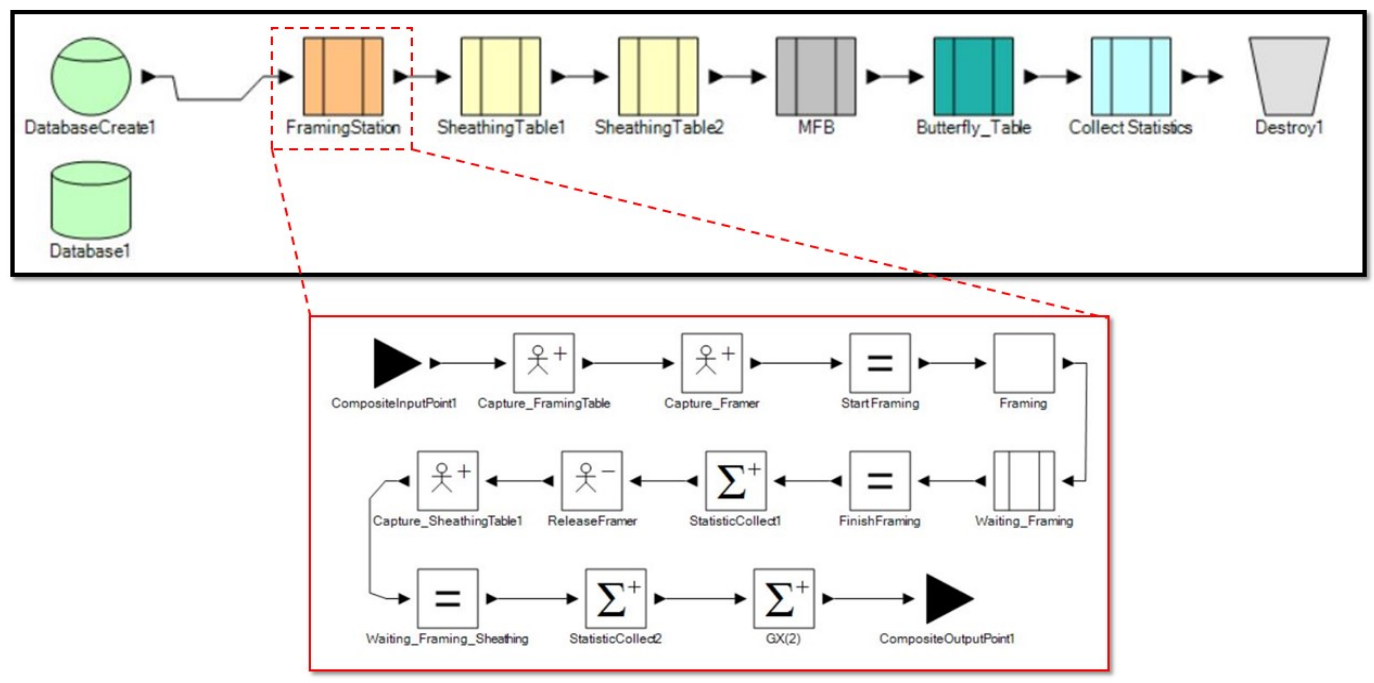

Figure 3: Simulation Model of the Multiwall Panel Manufacturing in Simphony.NET

For example, shown in Figure 3 are the details of operations at the framing station. These are as follows:

1. The simulation starts by capturing two types of resources: one worker and the framing table.

2. The starting time of framing operation is recorded in a local variable.

3. Framing activity starts, where the time required to frame a panel is found to be a function of the physical properties of the panel. The time to complete the framing of single panel $\mathrm{i}, \mathrm{FT}_{\mathrm{i}}$, is calculated using the following Equation 1:

Equation 1:

$$
\mathrm{FT}_{\mathrm{i}}=\left(\mathrm{t}_{\mathrm{Plt}, \mathrm{i}}+\mathrm{S}_{\mathrm{i}} * \mathrm{t}_{\mathrm{S}, \mathrm{i}}+\mathrm{D}_{\mathrm{i}} * \mathrm{t}_{\mathrm{D}, \mathrm{i}}+\mathrm{L}_{\mathrm{i}} * \mathrm{t}_{\mathrm{L}, \mathrm{i}}+\mathrm{O}_{\mathrm{i}} * \mathrm{t}_{\mathrm{O}, \mathrm{i}}+\mathrm{G}_{\mathrm{i}} * \mathrm{t}_{\mathrm{G}, \mathrm{i}}\right)+\mathrm{FD}_{i}
$$

where:

$t_{P l t, i}$ is the time required to load the top and bottom plates of the panel $i$

$S_{i}$ is the total number of regular studs in panel $\mathrm{i}$

$t_{S, i}$ is the time required to nail a single regular stud in panel $i$

$D_{i}$ is the total number of double studs in panel $i$

$t_{D, i}$ is the time required to nail a single double stud panel $i$

$\mathrm{L}_{\mathrm{i}}$ is the total number of L-shaped studs in panel $\mathrm{i}$

$t_{L, i}$ is the time required to nail a single L-shaped stud in panel $\mathrm{i}$

$\mathrm{O}_{\mathrm{i}}$ is the total number of small openings (windows and doors) in panel $\mathrm{i}$

$t_{0, i}$ is the time required to install a single small opening in panel $i$

$G_{i}$ is the total number of large openings (windows and doors) in panel $i$

$\mathrm{t}_{\mathrm{G}, \mathrm{i}}$ is the time required to install a single large opening in panel $\mathrm{i}$

$\mathrm{FD}_{i}$ are the delays in the framing process of the panel $\mathrm{i}$ 
4. The following five types of delays in the framing station $\left(\mathrm{FD}_{i}\right)$ were observed and simulated, checking plans, shortage of material, correcting errors, filling nail magazines, and workers slaking. The likelihood of occurrence for each type of delay, along with the average duration for each type, is calculated based on the collected observations. This information is used in the model to capture the actual state of the operation as it affects the total production duration of the wall panels and can cause a significant influence on the simulation results comparing to the actual state.

5. The total framing duration is then calculated as the difference between the current simulation time and the time stored earlier at the start of the operation.

6. The worker is released and is now available for the next wall panel.

7. To ensure that resources are available, before releasing the framing table, the next station, 'SheathingTable1', is captured, and waiting time is calculated.

Similar logic is used for subsequent stations, where resources are captured and released between operations. At each step, time differences between stations and operations are calculated and collected in 'statistics' containers, which are used later to calculate the total production duration, along with resource utilization and waiting time.

\section{MODEL VALIDATION}

As a validation of the simulation model, the results are compared with historical time stamps obtained from an RFID system. The total duration for each panel as obtained from the RIFD data is around 70 minutes, while the simulation result is around 64 minutes: a difference of approximately $8.5 \%$. Figure 4 represents the variation between the total duration as extracted from the RFID system and the total duration obtained from the simulation model for a sample of 100 multiwall panels.

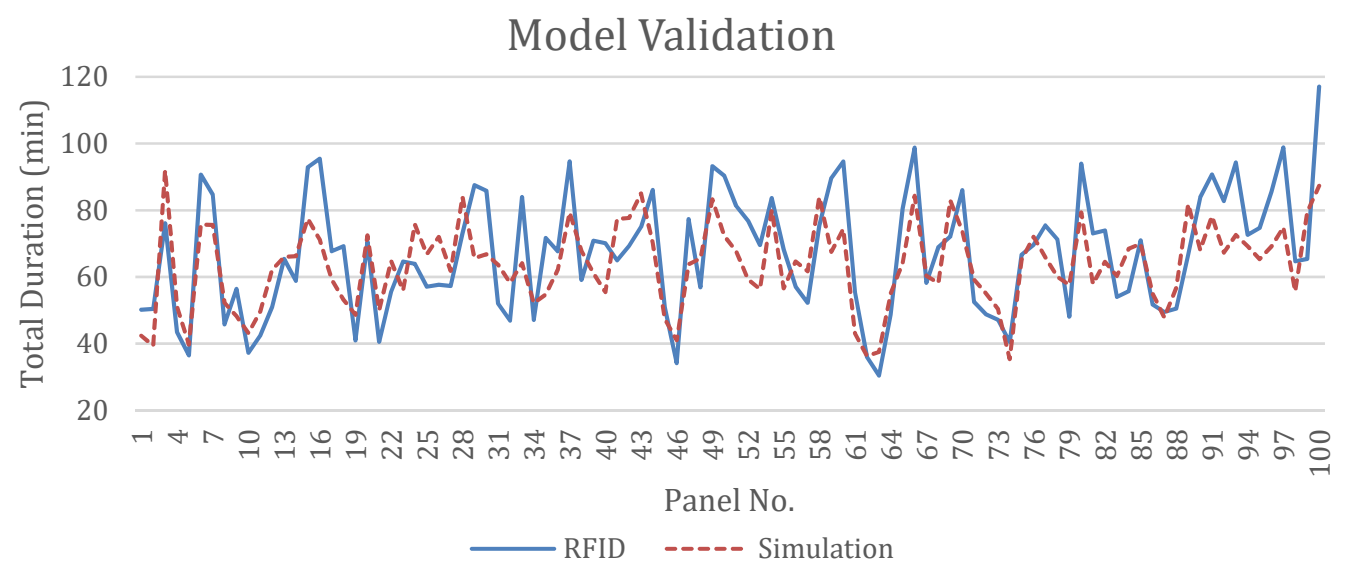

Figure 4: Model Validation - Comparing RFID and Simulation Results

\section{DATA ANALYSIS}

The simulation model of the current state is examined for multiple runs (100 runs) to take into account the variation in each tasks' duration since all the durations are modelled using mathematical distributions. An output analysis was performed on the averages of these 100 runs for each of the 2,900 multiwall panels produced in a one-year period. Along with obtaining the total production duration for each panel from the simulation 
results, we can also investigate each panel's total idle time during production due to an imbalance between the stations on the production line. From the simulation results, it can be noted that the average idle time (IT) represents about $20 \%$ of the total duration (TD) required to produce the panel and can account for as much as $75 \%$ of the total duration. Figure 5 shows the total duration as calculated using the simulation model for the same sample that was used for validation, along with the total idle time for each panel and the percentage of idle time with respect to the total duration.

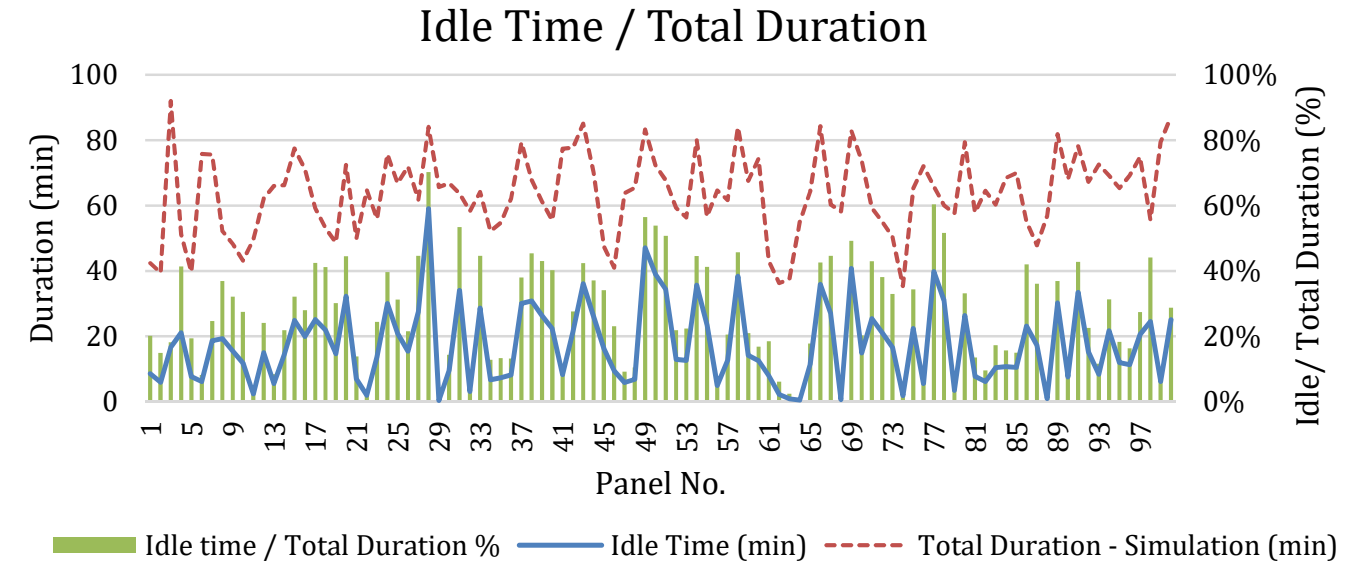

Figure 5: Percentage Idle Time / Total Duration

The utilization rate of each station on the production line is also examined and captured from the simulation output in order to determine any potential improvements. The goal is to speed up the production line by cutting the average idle time for each panel during production and reduce the total time each panel spends in the system. Table 1 illustrates the simulation results of each individual station, as captured from the simulation model.

Table 1: Current-State simulation results

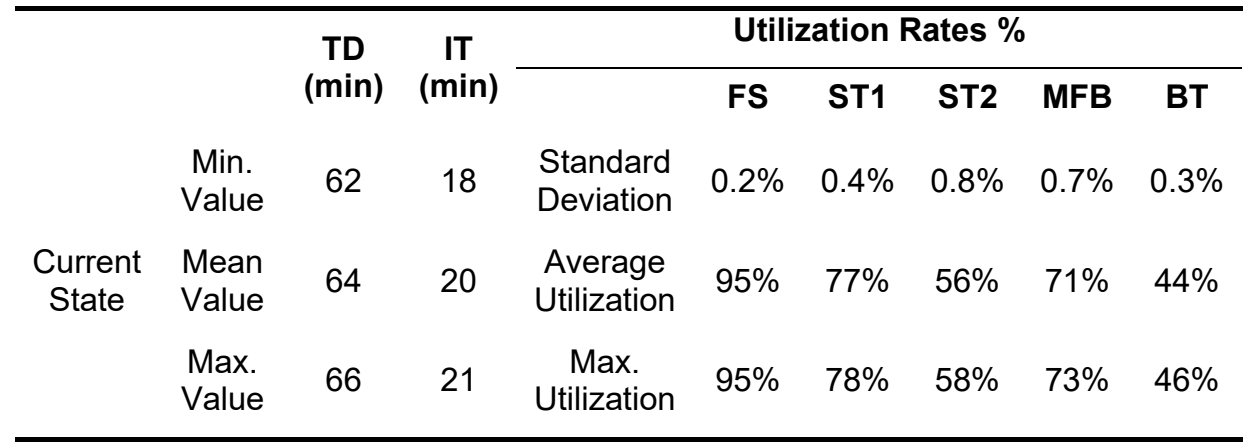

Since the framing station is the first station on the production line and in the simulation model, it is expected to have a utilization rate close to $100 \%$. In examining the following stations, there is a significant difference in the utilization rate between the first and second sheathing tables (77\% and 56\%, respectively), as well as between ST2 and MFB where the utilization rate of the MFB is $71 \%$. This variation can be attributed to idle time when production work on a panel is finished, but the panel must remain at the station until the next station is available. The main reason for the imbalance that causes idle time is the difference in the time required to perform the productive tasks at each station. 
Another key observation is that all the internal wall panels pass through all the stations of the production line, even though no tasks are performed on the interior wall panels at some of the stations. All the productive tasks required for the internal wall panels are completed at the first two stations (FS and ST1), but the panels still pass through the following stations, which increases the observed utilization rate of these stations without value-adding activities.

Based on the observations and data analysis, three potential improvement scenarios are examined with the goal of eliminating or reducing the waste on time. The objective is to decrease the idle time at each station and thus reducing the cycle time each panel spends on the system, which will result in higher average throughput. For the following data analysis, since the simulation model has been validated to produce accurate results compared to the actual state, only the obtained mean values are considered when performing the analysis and examining the improvement effect on the system performance.

\section{FIRST SCENARIO: REROUTING INTERIOR WALLS}

In this scenario, interior wall panels are rerouted from the main production flow after the first sheathing station (ST1) using a butterfly table. All the tasks performed on the current sheathing table will be carried out on the new butterfly table with the same task durations. The butterfly table will serve to move the interior wall panels directly to the loading bays where they are loaded on the trailers to be shipped without having to pass through all the stations of the production line. A revised version of the simulation model was developed to accommodate this change and was run for 100 runs. The results indicate that the implementation of the proposed scenario can lead to a reduction in the average total duration for wall panels from 64 minutes, on the current state model, to approximately 45 minutes. Similarly, the average idle time for each panel decreases from 22 minutes to approximately 12 minutes. The achieved results prove the high impact of implementing lean principles on the manufacturing process since the average idle time is reduced by $45 \%$. This scenario provides a potential reduction in the total production time required to produce the panels (TP) on the studied work-load by 27 hours. This can be reflected as a drop in the labour cost since the production time reduction can be expressed as a 189 man-hours ( $\mathrm{MH})$ saving as there are seven workers assigned to the studied stations. Table 2 summarizes the results of implementing this scenario on the average total duration of the panels and the utilization rate at each station.

Table 2: Scenario 1 Results

\begin{tabular}{|c|c|c|c|c|c|c|c|c|c|}
\hline & \multirow{2}{*}{$\begin{array}{c}\text { TD } \\
(\min )\end{array}$} & \multirow{2}{*}{$\begin{array}{c}\mathrm{IT} \\
(\mathrm{min})\end{array}$} & \multicolumn{5}{|c|}{ Average Utilization Rates \% } & \multirow{2}{*}{$\begin{array}{c}\text { TP } \\
\text { reduction } \\
\text { (hr) }\end{array}$} & \multirow{2}{*}{$\begin{array}{c}\text { MH } \\
\text { reduction } \\
\text { (hr) }\end{array}$} \\
\hline & & & FS & ST1 & ST2 & MFB & BT & & \\
\hline Scenario 1 & 45 & 12 & $95 \%$ & $72 \%$ & $44 \%$ & $51 \%$ & $10.8 \%$ & 27 & 189 \\
\hline
\end{tabular}

\section{Second Scenario: Enhanced Automated NaIling Machine}

The automated framing machine at FS is used to nail studs to the top and bottom plates. This operation sometimes results in errors when the nails do not go through or only halfway through the element, which requires removing the nails and manually nailing the elements at ST1. Based on this observation, in order to reduce the making of such defective parts, a new industrial nailing system is proposed to replace the existing one on FS, which can eliminate the task of error correction at the following station. 
The results of implementing this proposed improvement suggest a decrease in the total duration to 62 minutes, while the idle time increases to 26 minutes; however, the utilization rate of ST1 is reduced significantly. The explanation behind the increase in the average idle time in this scenario is deemed to the change on the system bottleneck, as we can notice that the new bottleneck is now the MFB, where an increase in the station's utilization is detected. Table 3 summarizes the results of implementing this scenario.

Table 3: Scenario 2 Results

\begin{tabular}{|c|c|c|c|c|c|c|c|c|c|}
\hline & \multirow{2}{*}{$\begin{array}{c}\text { TD } \\
(\min )\end{array}$} & \multirow{2}{*}{$\begin{array}{c}\mathrm{IT} \\
(\min )\end{array}$} & \multicolumn{5}{|c|}{ Average Utilization Rates \% } & \multirow{2}{*}{$\begin{array}{c}\text { TP } \\
\text { reduction } \\
\text { (hr) }\end{array}$} & \multirow{2}{*}{$\begin{array}{c}\text { MH } \\
\text { reduction } \\
\text { (hr) }\end{array}$} \\
\hline & & & FS & ST1 & ST2 & MFB & BT & & \\
\hline Scenario 2 & 62 & 26 & $95 \%$ & $55 \%$ & $66 \%$ & $77 \%$ & $49 \%$ & 22 & 154 \\
\hline
\end{tabular}

\section{THIRD SCENARIO: COMBINATION OF THE FIRST Two SCENARIOS}

This scenario examines the simultaneous implementation of the previous two scenarios. The results obtained from the implementation of this scenario prove the high effect of this change on the whole system performance. The improvement in the production process flow is significant, as the idle time is reduced by $35 \%$ while the average cycle time of each panel is reduced by $42 \%$. Additionally, a 58 hours potential reduction on the TP can be obtained, which can be reflected as a reduction of 406 man-hours.

Moreover, this scenario can reduce the utilization rate of all the stations following the framing station, which can lead to a reduction in the number of resources required at these stations without affecting the production flow or the cycle time of the panels. Table 4 presents the results of implementing this scenario.

Table 4: Scenario 3 Results

\begin{tabular}{|c|c|c|c|c|c|c|c|c|c|}
\hline & \multirow{2}{*}{$\begin{array}{c}\text { TD } \\
(\min )\end{array}$} & \multirow{2}{*}{$\begin{array}{c}\mathrm{IT} \\
(\mathrm{min})\end{array}$} & \multicolumn{5}{|c|}{ Average Utilization Rates \% } & \multirow{2}{*}{$\begin{array}{c}\text { TP } \\
\text { reduction } \\
\text { (hr) }\end{array}$} & \multirow{2}{*}{$\begin{array}{c}\text { MH } \\
\text { reductior } \\
(\mathrm{hr})\end{array}$} \\
\hline & & & FS & ST1 & ST2 & MFB & BT & & \\
\hline Scenario 3 & 37 & 13 & $95 \%$ & $40 \%$ & $48 \%$ & $54 \%$ & $12 \%$ & 58 & 406 \\
\hline
\end{tabular}

\section{CONCLUSION}

Using DES, this paper explores potential improvements in the production flow in a manufacturing facility of panelized modular homes. The focus of this study is the production line of multiwall panels, where three different improvement scenarios are examined. The first improvement scenario suggests that making modifications to the process flow and the floor layout, by replacing the second workstation (ST1) with a butterfly table, would reduce the idle time by approximately $40 \%$ and reduce the total duration by $30 \%$. The second scenario suggests that improving the first workstation (FS), by replacing the current nailing system with a new more efficient one, might have a less significant impact by reducing the total duration by only $4 \%$ while increasing the idle time by $30 \%$. However, a third scenario that combines the aforementioned two scenarios results in the most significant overall improvement, where the cycle time would be reduced by $42 \%$, and the idle time would be reduced by $35 \%$. Moreover, using the third scenario, the utilization rate of most workstations is decreased, which indicates that fewer resources could be used in that scenario. Overall, by implementing the third scenario, the same number of panels would require about eight fewer days to produce in comparison 
with the current production state, which translates to producing 42 panels/day in comparison with 36 panels/day currently produced, on average.

Recommendations for future research include investigating the cost of change associated with the proposed scenarios as well as exploring any potential improvements on the rest of the production line. Also, further studies can be conducted to investigate the utilization and idle time on each station on the production line in more detail.

\section{ACKNOWLEDGMENTS}

The authors wish to acknowledge the financial support of the Natural Sciences and Engineering Research Council of Canada (NSERC) as well as the assistance and support of ACQBUILT, Alberta, Canada.

\section{REFERENCES}

AbouRizk, S., Hague, S., Ekyalimpa, R., and Newstead, S. (2014). "Simphony: a next generation simulation modelling environment for the construction domain." $J$. of Simulation, Nature Publishing Group, 10(3), 207-215.

AbouRizk, S. and Hajjar, D. (2011). "A framework for applying simulation in construction." Canadian J. of Civil Engineering, 25(3), 604-617.

Akhavian, R. and Behzadan, A.H. (2011). "Dynamic simulation of construction activities using real time field data collection.” EG-ICE 2011, European Group for Intelligent Computing in Engineering, 1-8.

Altaf, M.S., Liu, H., Al-Hussein, M., and Yu, H. (2016). "Online simulation modeling of prefabricated wall panel production using RFID system.” Proc. Winter Simulation Conf., 3379-3390.

Chauhan, K., Peltokorpi, A., Lavikka, R., and Seppänen, O. (2019). "Deciding between prefabrication and on-site construction: A choosing-by-advantage approach." Proc. 27th Ann. Conf. Int. Group for Lean Construction, Dublin, Ireland, 749-758.

Garza-Reyes, J.A., Oraifige, I., Soriano-Meier, H., Forrester, P.L., and Harmanto, D. (2012). "The development of a lean park homes production process using process flow and simulation methods." J. of Manufacturing Technology Management.

Gupta, A., Gonzalez, V., and Miller, G. (2012). "Understanding the relationship between productivity and buffers in construction: A simulation-based case." Proc. 20th Ann. Conf. Int. Group Group for Lean Construction.

Hermes, M. (2015). "Prefabrication \& modularization as a part of lean construction status quo in Germany." Proc. 23rd Ann. Conf. Int. Group for Lean Construction: Global Knowledge - Global Solutions, 235-245.

Koskela, L. (1992). "Application of the New Production Philosophy to Construction." Technical Rep. No. 72, Center for Integrated Facility Eng., Dept. of Civil Engineering, Stanford Univ., Stanford, Calif.

Koskela, L. , Bølviken, T., and Rooke, J. 2013. "Which Are the Wastes of Construction?" In: Formoso, C.T. and Tzortzopoulos, P., Proc. 21th Ann. Conf. Int. Group for Lean Construction, Fortaleza, Brazil, pp. 3-12.

Lu, M. (2003). "Simplified Discrete-Event Simulation Approach for Construction Simulation." J. Construction Engineering and Management, 129(5), 537-546.

Moghadam, M. (2014). Lean-mod: an approach to modular construction manufacturing production efficiency improvement. University of Alberta, $\mathrm{PhD}$ diss.

Mohsen, O., Abdollahnejad, S., Sajadfar, N., Mohamed, Y., and AbouRizk, S. (2018). "Modeling and simulation of cabinet manufacturing processes: evaluation and 
recommended controls." Proc. 17th Int. Conf. on Modeling and Applied Simulation (MAS 2018), Budapest, Hungary, 146-152.

Ritter, C., Zhang, Y., Dupuis, R., and Al-Hussein, M. (2017). "Simulation of Production Line Improvement in Modular Home Manufacturing." Proc. 25th Ann. Conf. Int. Group for Lean Construction, 737-744.

Schramm, F.K., Silveira, G.L., Paez, H., Mesa, H., Formoso, C.T.V., and Echeverry, D. (2008). "Using discrete-event simulation to support decision-makers in production system design and operations." Proc. 16th Ann. Conf. Int. Group for Lean Construction, 131-141.

Shou, W., Wu, P., and Wang, J. (2019). "A survey of simulation modelling techniques in lean construction research." Proc. 27th Ann. Conf. Int. Group for Lean Construction, Dublin, Ireland, 1093-1104.

Velarde, G.J., Saloni, D.E., van Dyk, H., and Giunta, M. (2009). "Process flow improvement proposal using lean manufacturing philosophy and simulation techniques on a modular home manufacturer." Lean Construction J., 77-93.

Vrijhoef, R. (2016). "Effects of Lean Work Organization and Industrialization on Workflow and Productive Time in Housing Renovation Projects." Proc. 24th Ann. Conf. Int. Group for Lean Construction, Boston, Mass., USA. 